\title{
Redesign Web Sekolah Metode User Centered Design
}

\author{
Yoyon Efendi ${ }^{1{ }^{1 *},}$ Tashid $^{2}$, Helda Yenni ${ }^{3}$, Unang Rio $^{3}$, Rometdo Muzawi $^{3}$ \\ ${ }^{1}$ Teknologi Informasi, STMIK Amik Riau, Pekanbaru, Indonesia \\ ${ }^{2}$ Sistem Informasi, STMIK Amik Riau, Pekanbaru, Indonesia \\ ${ }^{3}$ Teknik Informatika, STMIK Amik Riau, Pekanbaru, Indonesia \\ Email: ${ }^{1}$ yoyonefendi@stmik-amik-riau.ac.id, ${ }^{2}$ tashid@ sar.ac.id, ${ }^{3}$ heldayenni@sar.ac.id, ${ }^{4}$ unangrio@sar.ac.id, \\ 5rometdomuzawi@sar.ac.id \\ Email Penulis Korespondensi: yoyonefendi@stmik-amik-riau.ac.id \\ Submitted: 20/12/2021; Accepted: 27/12/2021; Published: 31/12/2021
}

\begin{abstract}
Abstrak-Web sangat diperlukan sebagai media promosi sekolah untuk menarik minat dan info tentang sekolah. Web ini nantinya digunakan untuk mempermudah baik guru, murid, maupun wali murid. Masalah yang sering kita hadapi tampilan website tidak menarik serta kurang informatif. Mulai dari warna yang tidak menarik juga berita dan informasi tidak di update. Diperlukan redesign web sekolah agar memberikan tampilan yang menarik dan informatif. Metode pada penelitian ini menggunakan User Centered Design (UCD) mulai dari Plan, Design, Prototype dan review. Penelitian ini bertujuan untuk menghasilkan website SMK Negeri 1 Perhentian Raja yang informatif dan disukai oleh pengguna.
\end{abstract}

Kata Kunci: Web; Sekolah; Redesign; UCD; SMK N 1 Perhentian Raja

Abstract-The web is indispensable as a medium for school promotions to attract interest and information about schools. This website will be used to make it easier for both teachers, students, and guardians of students. The problem we often face is that the appearance of the website is unattractive and less informative. Starting from unattractive colors, news and information are not updated. It is necessary to redesign the school web to provide an attractive and informative appearance. The method in this research uses User Centered Design (UCD) starting from Plan, Design, Prototype and review. This study aims to produce a website for SMK Negeri 1 Perhentian Raja that is informative and liked by users.

Keywords: Web; School; Redesign; UCD; SMK N 1 Perhentian Raja

\section{PENDAHULUAN}

SMK N 1 Perhentian Raja merupakan sekolah yang berada di Kabupaten Kampar Provinsi Riau. Masalah yang dihadapi seperti web sekolah yang kurang menarik dan kurang informatif. Selain itu juga data kurang update dan sulit menemukan menu atau fitur yang dibutuhkan seperti form siswa baru, ektrakurikuler dan lainnya.

Ditambah dengan pandemi yang tak berkesudahan membuat sekolah semakin sulit dalam melaksanakan proses belajar mengajar. Kurangnya tenaga IT disekolah tersebut juga semakin memperburuk keadaan. Lanjut kepala sekolah juga mengatakan pemahaman guru, murid, serta wali murid mengenai internet juga masih kurang disebabkan oleh buruknya konektifitas internet dan berbagai macam hal lainnya.

Semakin cepatnya perkembangan zaman, membuat segala hal harus terhubung dengan internet, tak terkecuali sekolah. Tidak maksimalnya penggunaan teknologi di sekolah-sekolah khusnya yang berada di daerah terpencil menyebabkan sekolah-sekolah tersebut susah untuk bersaing dengan sekolah yang berada di kota baik dari mutu pendidikan maupun urusan administrasi. Impian untuk penyamarataan kualitas pendidikan di Indonesia tidak akan tercapai jika daerah-daerah terpencil masih kurang mendapatkan literasi mengenai internet. Salah satu langkah awalnya adalah dengan membuat website resmi sekolah dengan tampilan antarmuka yang simpel serta mudah dipahami bagi orang awam.

Website atau situs dapat diartikan sebagai kumpulan halaman-halaman yang digunakan untuk menampilkan informasi teks, gambar diam atau gerak, animasi suara, dan atau gabungan dari semuanya baik yang bersifat statis maupun dinamis yang membentuk satu rangkaian bangunan yang saling terkait, yang maing-masing dihubungkan dengan jaringan-jaringan halaman[1]. Website ini nantinya juga berguna sebagai jembatan bagi murid dan guru. Semisal guru bisa memposting berita dan pengumuman yang penting di website tersebut dengan harapan para siswa dan wali murid bisa mendapatkan informasi lebih cepat dan akurat. Website adalah kumpulan dari halaman-halaman situs, yang terangkum dalam sebuah domain atau subdomain, yang tempatnya berada di dalam World Wide Web ( WWW ) di dalam internet[2].

Mengingat seringnya terjadi kehilangan data di SMAN 1 Rangsang, tenaga pengajar juga bisa mengunakan website ini untuk menyimpan data-data sekolah semisal absensi, batas belajar siswa, dsb, dan pastinya memiliki keamanan data yang lebih terjaga. Lebih baik lagi informasi mengenai absensi dan batas belajar siswa bisa ditampilkan secara transparan, agar murid dan wali murid juga bisa mengaksesnya, bahasa sederhananya wali murid bisa tahu kegiatan anaknya selama disekolah.

Sebuah desain interface merupakan tampilan yang akan memberikan sebuah hasil perpaduan antara input dari desain yang baik dan output mekanisme yang akan memuaskan kebutuhan user, kemampuan, dan limitasi dengan cara yang seefektif mungkin, sebuah interface yang baik tidak akan terasa oleh user, dan akan menkontrol user untuk fokus pada informasi yang dipresentasikan[3]. User interface merupakan komponen yang tidak dapat dipisahkan dengan aplikasi yang bertugas menghubungkan antara aplikasi dengan pengguna agar dapat berinteraksi dengan mudah[4]. 


\section{METODOLOGI PENELITIAN}

Penelitian ini dimulai dengan plan lalu design menggunakan wireframe figma dan balsamiq. Figma adalah salah satu design tool yang biasanya digunakan untuk membuat tampilan aplikasi mobile, desktop, website dan lain-lain[5]. Figma adalah aplikasi desain berbasis cloud dan alat prototyping untuk proyek digital. Figma dibuat untuk dapat membantu para penggunanya agar bisa berkolaborasi dalam proyek dan bekerja dalam bentuk tim sekaligus di mana saja[6].

Balsamiq merupakan software yang telah banyak digunakan oleh para desainer web sebelum membuat sebuah Website dan aplikasi, hal ini dilakukan agar mereka bisa membuat sebuah desain Website yang bukan hanya menarik dari sisi tampilan, tapi juga sesuai dengan kebutuhan Customer[7].

Setelah hasil dari penelitian diatas didapatkan, kami langsung melakukan analisa terhadap data tersebut dan mulai untuk membangun prototype website berdasarkan design yang telah dibuat sebelumnya. Prototype adalah Prototype adalah model kerja dasar dari pengembangan sebuah program (software) atau perangkat lunak[5]. prototyping merupakan metode pengembangan perangat lunak, yang berupa model fisik kerja sistem dan berfungsi sebagai versi awal dari sistem. Dengan metode prototyping ini akan dihasilkan prototype sistem sebagai perantara pengembang dan pengguna agar dapat berinteraksi dalam proses kegiatan pengembangan sistem informasi[8] Metode Prototyping menurut Ogedebe dan Peter Jacob merupakan metode pengembangan perangat lunak, yang berupa model fisik kerja sistem dan berfungsi sebagai versi awal dari sistem[9].

Tahapan dalam prototyping adalah sebagai berikut : pertama Pengumpulan kebutuhan, kedua proses desain cepat, ketiga. membangun prototype evaluasi dan perbaikan. Langkah terakhir yakni mereview design terkait penelitian ini berdasarkan data-data yang telah didapatkan [10].

\subsection{Tahapan Penelitian}

Metode penelitian yang kami gunakan adalah User Centre Design (UCD), yakni merupakan metode yang biasa dipakai oleh developer dan designer sebuah produk digital agar dapat membuat rancangan senyaman mungkin digunakan oleh user. Metode user centered design merupakan sebuah pendekatan untuk pengembangan user interface dan pengembangan sistem[11]. Bentuk pengaplikasiannya pertama kami memulai dengan melakukan planing untuk memulai penelitian.

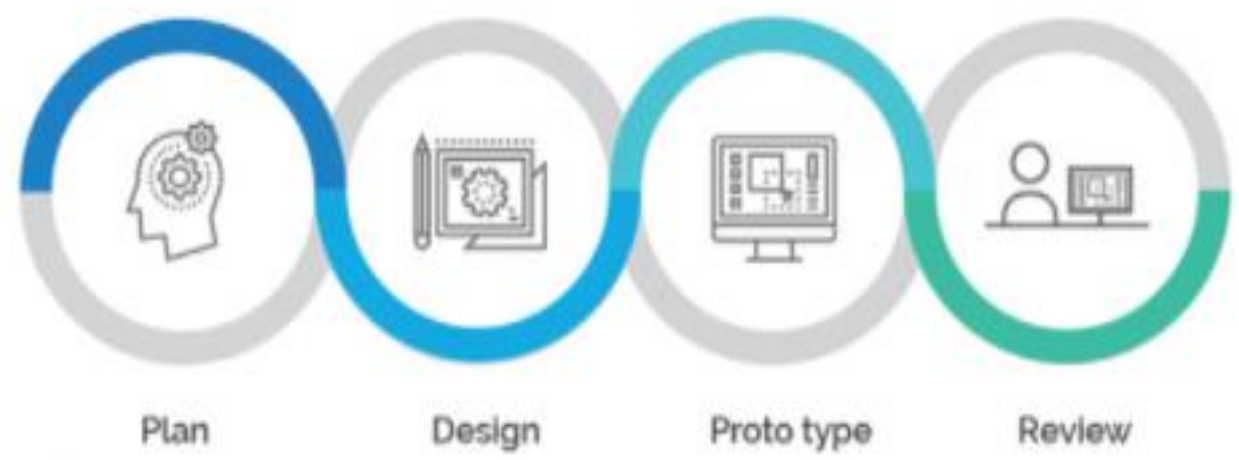

Gambar 1. Tahapan penelitian User Centered Design (UCD)

\section{Plan}

Dalam tahap ini, kami melakukan perencanaan dengan cara berdiskusi dengan dosen pembimbing terkait penelitian, mulai dari tempat penelitian, konsep penelitian yang akan diterapkan, dan lain-lain. Kami juga berdiskusi mengenai observasi. Hasilnya adalah dengan menerapkan dua cara. Pertama, perwakilan tim secara langsung mendatangi SMK N 1 Perhentian Raja untuk mewawancarai Indra Putra, S.Kom. Kedua, pembuatan google form berisi tentang pertanyaan-pertanyaan yang nantinya akan dibagikan langsung ke murid SMK N 1 Perhentian Raja melalui media sosial.

\section{Design}

Penelitian dilakukan dengan dua tahapan pada bagian ini. Pertama, melakukan desain kasar menggunakan Wireframe Balsamiq, sedangkan untuk design akhir menggunakan figma. Wireframe merupakan kerangka dasar atau blueprint dari satu halaman aplikasi yang akan dibangun oleh pengembang aplikasi. Sedangkan Figma adalah salah satu design tool yang biasanya digunakan digunakan untuk membuat tampilan aplikasi mobile, desktop, website dan lain-lain. Kedua tools ini bisa dikatakan adalah pilihan terbaik bagi para developer untuk mendesign suatu tampilan web.

\section{Prototype}

Setelah mendapatkan data dari observasi, kemudian kami berdiskusi untuk menganalisis hasil dari data tersebut. Banyak yang kami analisis, salah satunya adalah tampilan website seperti apa yang mestinya dibuat berdasarkan data 
yang didapatkan. Langkah selanjutnya adalah membangun prototype web berdasarkan design sebelumnya, kami membangun web ini menggunakan bahasa pemrograman html, css, javascript, dan php.

\section{Review}

Berdasarkan analisa tentang efektifitas penggunaan website untuk instansi pendidikan, yang mana penelitian ini bertujuan untuk memudahkan kegiatan belajar mengajar di SMK N 1 Perhentian Raja. Proses ini akan menjadi hasil apakah penelitian ini dapat dilanjutkan atau tidak.

\section{HASIL DAN PEMBAHASAN}

Dalam penelitian ini, didapat hasil kuesioner yang di isi oleh 20 orang siswa, karyawan dan guru di SMK N 1 Perhentian Raja. Maka dapat tabel dan grafik sebagai berikut:

Tabel 1. Hasil Kuesioner sebelum Redesign Web Sekolah

\begin{tabular}{cll}
\hline No & \multicolumn{1}{c}{ Nama } & Status \\
\hline 1 & Aulio Nauval Falandy Subekti & Siswa \\
2 & Tri Rahmat Aprianto & Siswa \\
3 & Septi Wulandari & Siswa \\
4 & Galing Afrian Prasetio & Siswa \\
5 & Saris Agus & Siswa \\
6 & Ahmad Fkhi Fatahillah & Siswa \\
7 & Muhammad Riski & Siswa \\
8 & Gibran wahyu nirwana & Siswa \\
9 & Ika Nur Riskiyanti & Siswa \\
10 & Bimo Pratama & Siswa \\
11 & Rina Purwati, S.Pd & Guru \\
12 & Setyana Dwi Fatmawati, S.Pd & Guru \\
13 & Resty Ika Prahesti, S.Pd & Guru \\
14 & Eko Rianto & Karyawan \\
15 & Aynul Yazin & Guru \\
16 & Nur Anisyah & Guru \\
17 & Citra Ayu Rahmawati & Guru \\
18 & Sis Joko N & Guru \\
19 & Sri Indra Putra S & Guru \\
20 & Ainul Yakin, ST & Guru \\
\hline
\end{tabular}

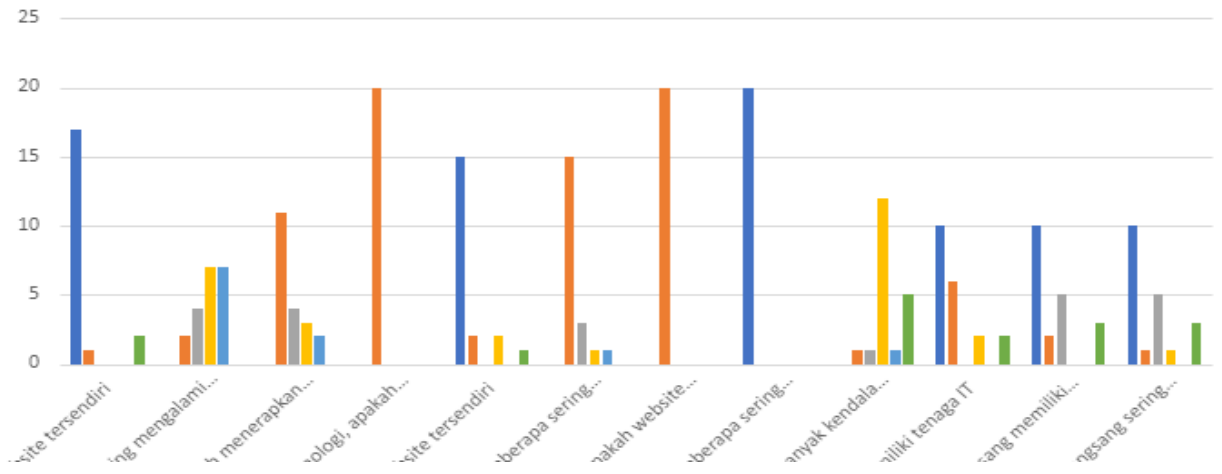

Gambar 2. Grafik Kuesioner sebelum redesign web sekolah

Hasil yang didapat berdasarkan grafik diatas, masih banyak siswa yang kurang meengakses web sekolah karena mulai dari tampilan yang tidak menarik, kurang informatif, konten tidak update dan koneksi internet yang kurang stabil. Selain itu, siswa kurang mendapatkan literasi dan pemahaman yang baik mengenai penerapan teknologi internet disekolah, kemungkinan disebabkan oleh kurangnya tenaga IT. Akibat lainnya adalah website yang dimiliki oleh sekolah tidak memiliki sistem antar muka yang mudah di pahami, dan website tersebut terlihat sudah lama tidak diperbaharui, sehingga pengunjung akan kesulitan ketika memahami website tersebut. Dan kegiatan belajar mengajar dan administrasi masih banyak dilakukan secara manual, menyebabkan sering terjadi kehilangan data akibat tingkat keamanan yang kurang. 
Building of Informatics, Technology and Science (BITS)

Volume 3, No 3, December 2021, Page 317-324

ISSN 2684-8910 (media cetak)

ISSN 2685-3310 (media online)

DOI 10.47065/bits.v3i3.1098
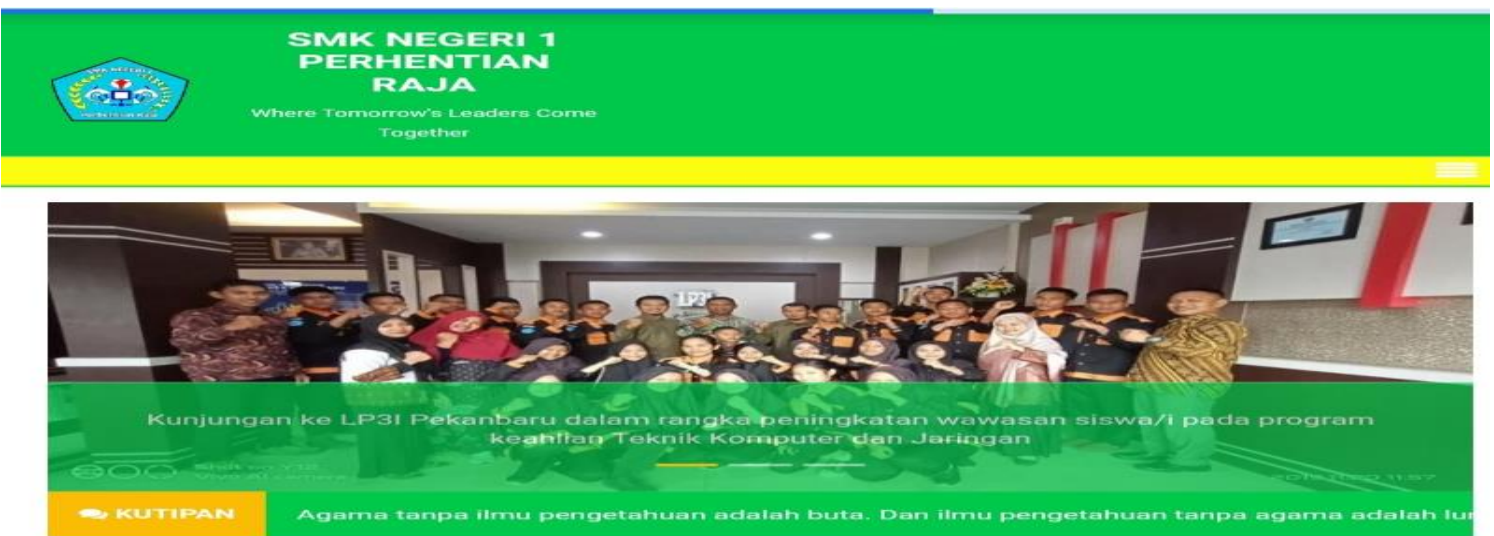

Tulisan Terbaru

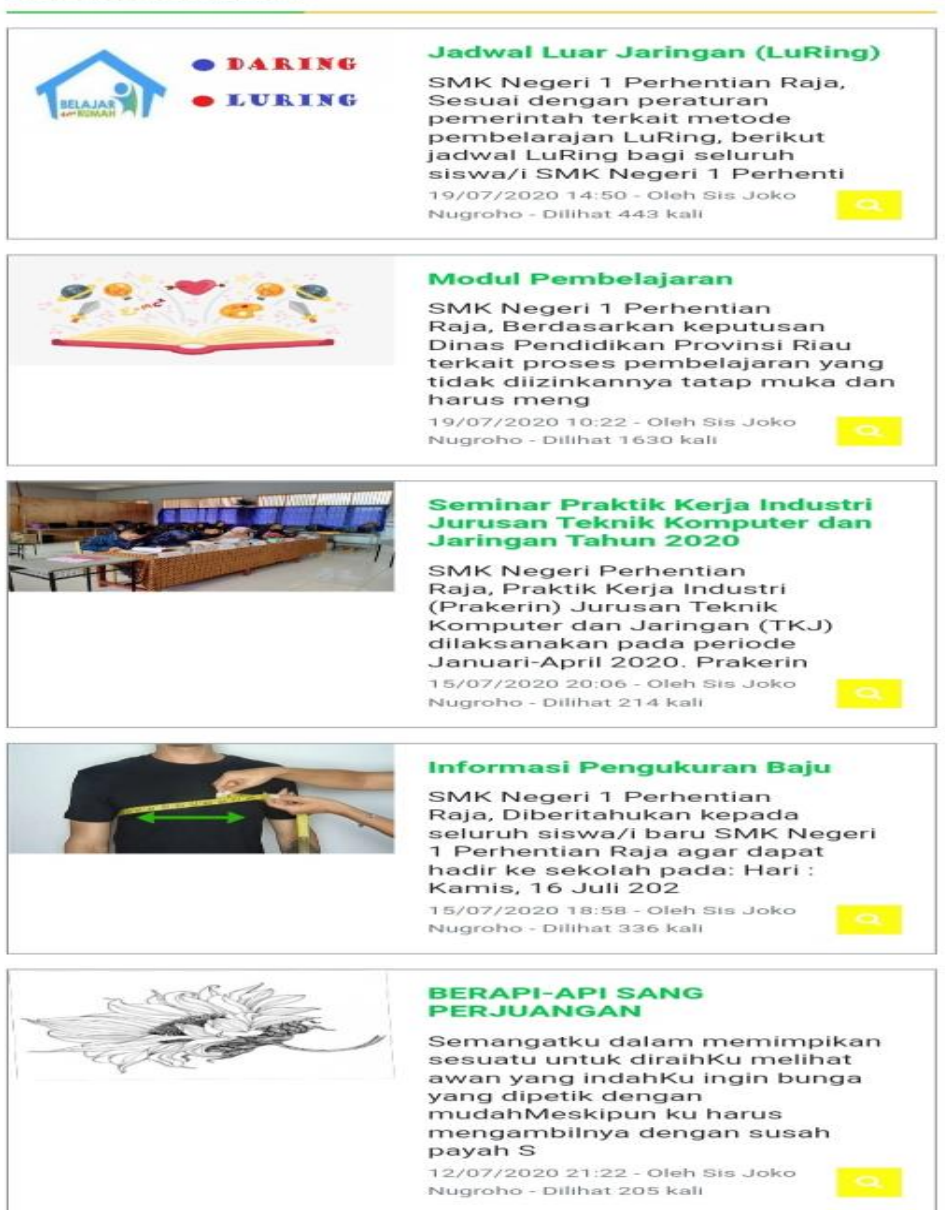

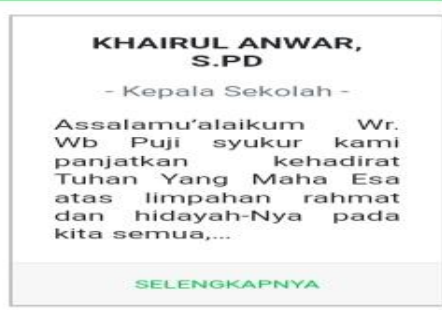

\section{Paling Dikomentari}

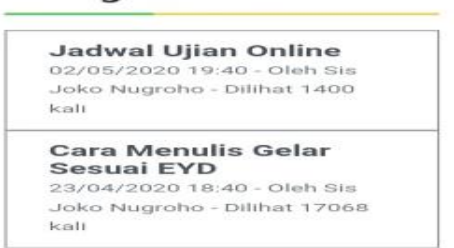

Berlangganan

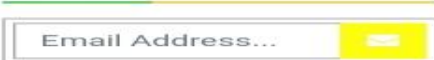

Iklan

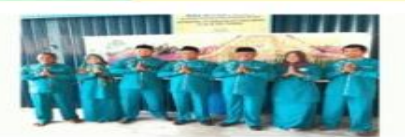

Gambar 3. Web sekolah sebelum di Redesign

Tampilan diatas merupakan website asli milik SMK N 1 Perhentian Raja. Terlihat warna nya terlalu cerah sehingga beberapa icon-icon tidak terlihat karena berwarna kuning dan background putih. Selain itu web tidak di perbaharui dan memiliki sistem antarmuka yang terlalu kaku.

\section{Plan}

Pada tahap plan, penelitian dilakukan dengan membuat sketsa di kertas gambaran dari redesign web secara utuh dan keseluruhan. Gambar dari sketsa dari SMK N 1 Perhentian Raja sebagai berikut: 


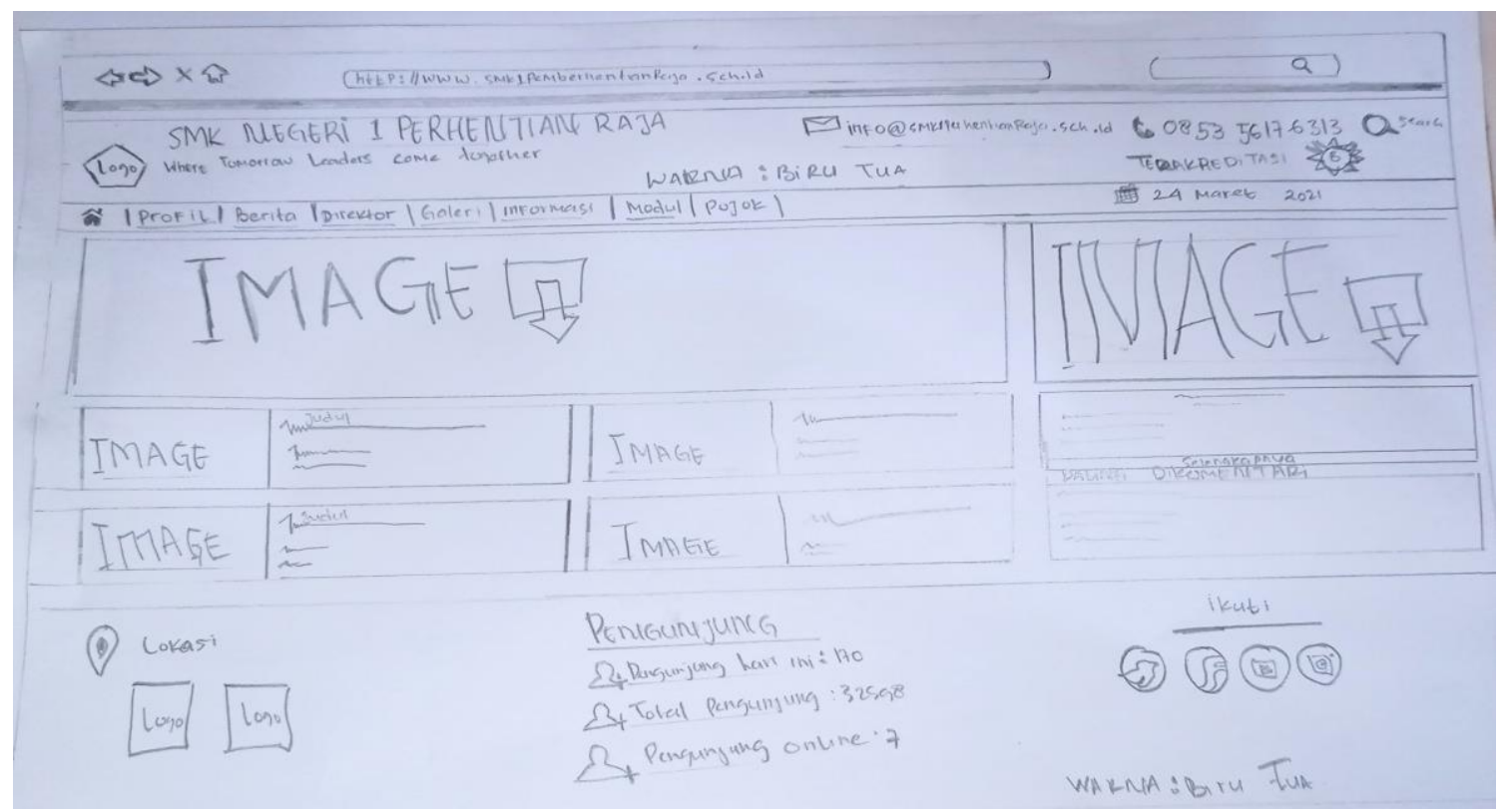

\section{Design}

Gambar 4. Desain sketsa di kertas pada proses plan

Pada tahap design dilakukan menggunakan tool wireframe yang dikenal dengan balsamiq. Pada tahap ini tampilan sudah terlihat tapi masih kasar dan pewarnaan masih standar. Tampilan balsamiq SMK N 1 Perhentian Raja dapat dilihat pada gambar berikut:

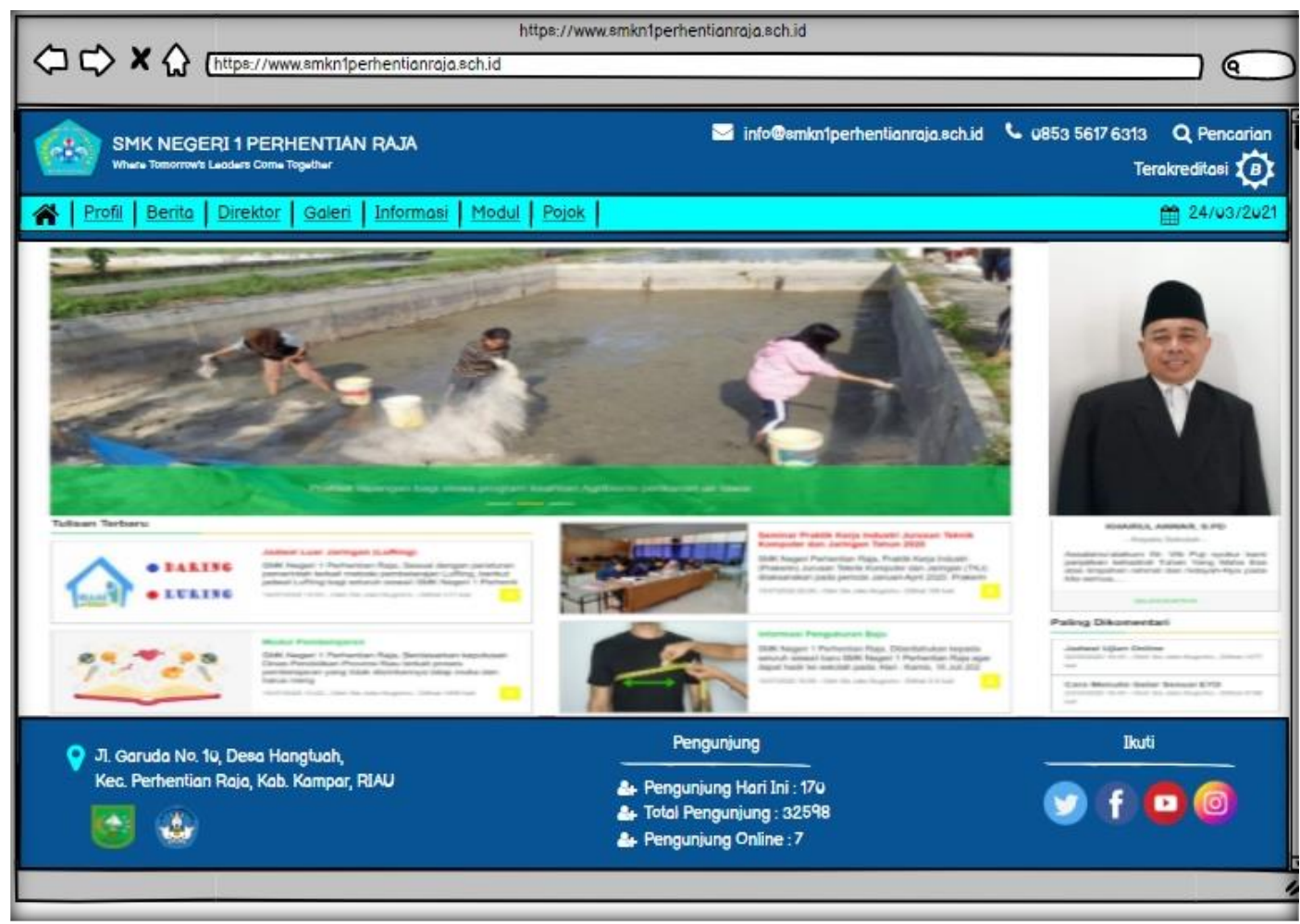

\section{Prototyping}

Gambar 5. Tampilan wireframe menggunakan balsamiq

Pada tahap prototyping menggunakan software figma. Pada tahap ini penyempurnaan redesign web secara sempurna dan menghasilkan tampilan lebih halus dan menarik. Tampilan hasil figma dapat dilihat dengan beberapa desain mulai dari header, body dan footer serta keseluruhan.

a. Header

Pada header dapat dilihat perbedaan dari sebelum redesdign dan sesudah redesign. Dengan tampilan sebagai berikut: 


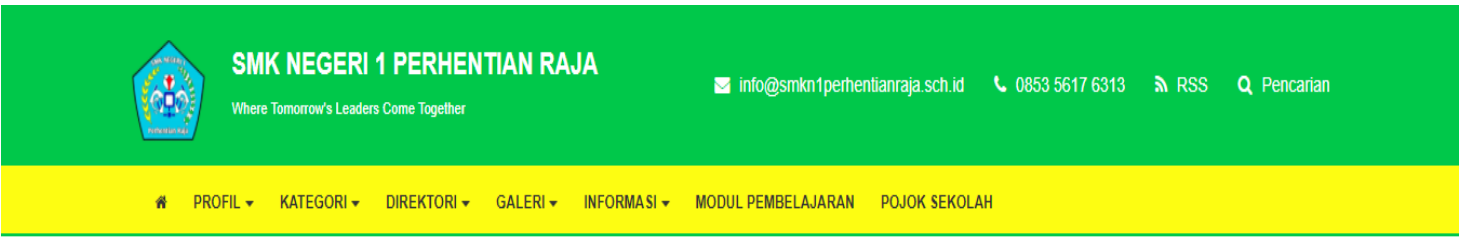

Gambar 6. Tampilan header sebelum redesign

ST. SMK NEGERI 1 PERHENTIAN RAJA
Where Tomorrow's Leaders Come Together

Gambar 7. Tampilan header setelah redesign figma

Pada tampilan dari redesign header menggunakan figma terlihat warna setelah redesign lebih menarik dan font dari header lebih terbaca dengan jelas.

b. Body

Pada body dapat dilihat perbedaan dari sebelum redesdign dan sesudah redesign. Dengan tampilan sebagai berikut:

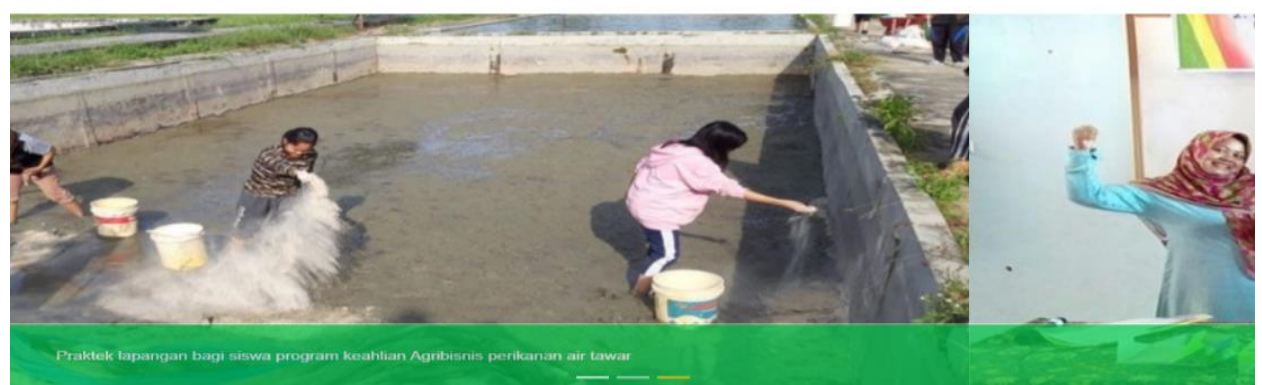

Gambar 8. Tampilan body sebelum redesign

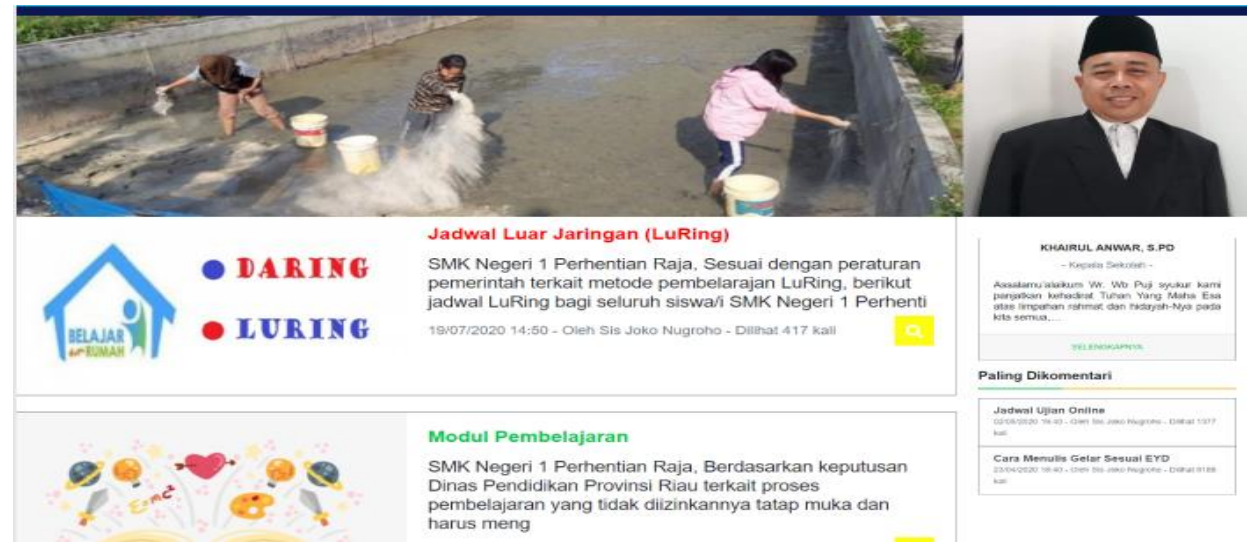

Gambar 9. Tampilan body setelah redesign figma

Pada tampilan dari redesign body menggunakan figma terlihat warna setelah redesign lebih menarik dan font dari body lebih terbaca dengan jelas.

c. Footer

Pada footer dapat dilihat perbedaan dari sebelum redesdign dan sesudah redesign. Dengan tampilan sebagai berikut:

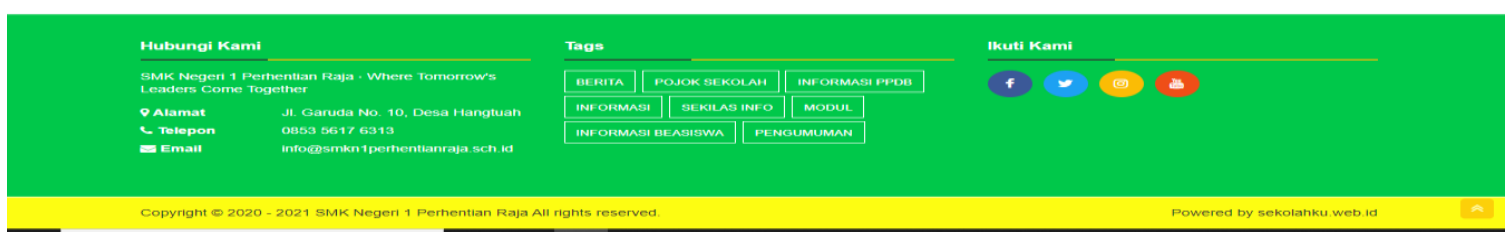

Gambar 10. Tampilan body sebelum redesign 


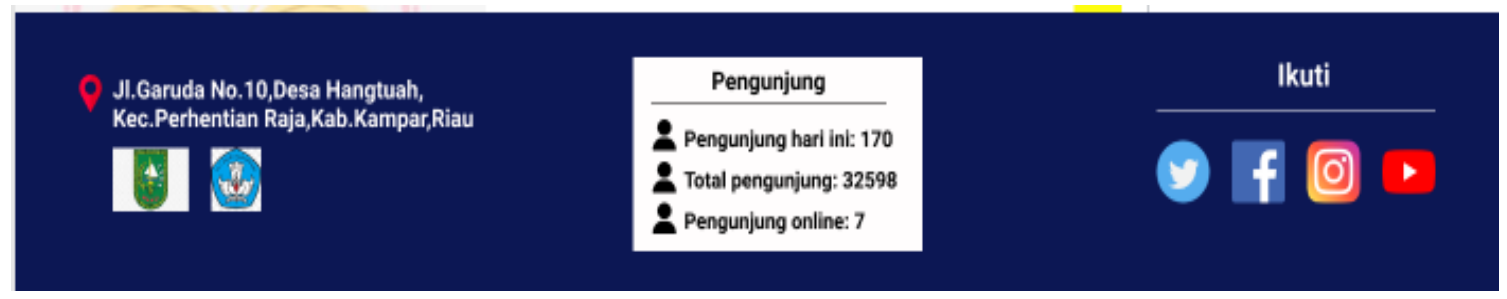

Gambar 11. Tampilan footer setelah redesign figma

Pada tampilan dari redesign footer menggunakan figma terlihat warna setelah redesign lebih menarik dan font dari footer lebih terbaca dengan jelas. Selain itu media sosial tersusun rapi dan ditambahkan fasilitas trafik kunjungan web.

4. Review

Pada tahap review dilakukan oleh siswa, guru, karyawan dan kepala sekolah. Dengan melihat hasil tampilan setelah redesign web sekolah, maka didapat hasil table dan grafik sebagai berikut:

Tabel 2. Hasil Kuesioner setelah Redesign Web Sekolah

\begin{tabular}{clcc}
\hline No & \multicolumn{1}{c}{ Nama } & Status & Hasil \\
\hline 1 & Aulio Nauval Falandy Subekti & Siswa & Baik \\
2 & Tri Rahmat Aprianto & Siswa & Baik \\
3 & Septi Wulandari & Siswa & Baik \\
4 & Galing Afrian Prasetio & Siswa & Sangat Baik \\
5 & Saris Agus & Siswa & Baik \\
6 & Ahmad Fkhi Fatahillah & Siswa & Baik \\
7 & Muhammad Riski & Siswa & Baik \\
8 & Gibran wahyu nirwana & Siswa & Baik \\
9 & Ika Nur Riskiyanti & Siswa & Sangat Baik \\
10 & Bimo Pratama & Siswa & Baik \\
11 & Rina Purwati, S.Pd & Guru & Baik \\
12 & Setyana Dwi Fatmawati, S.Pd & Guru & Baik \\
13 & Resty Ika Prahesti, S.Pd & Guru & Baik \\
14 & Eko Rianto & Karyawan & Sangat Baik \\
15 & Aynul Yazin & Guru & Baik \\
16 & Nur Anisyah & Guru & Baik \\
17 & Citra Ayu Rahmawati & Guru & Baik \\
18 & Sis Joko N & Guru & Sangat Baik \\
19 & Sri Indra Putra S & Guru & Baik \\
20 & Ainul Yakin, ST & Guru & Sangat Baik \\
\hline
\end{tabular}

\section{Hasil Evaluasi Redesign Web Sekolah}

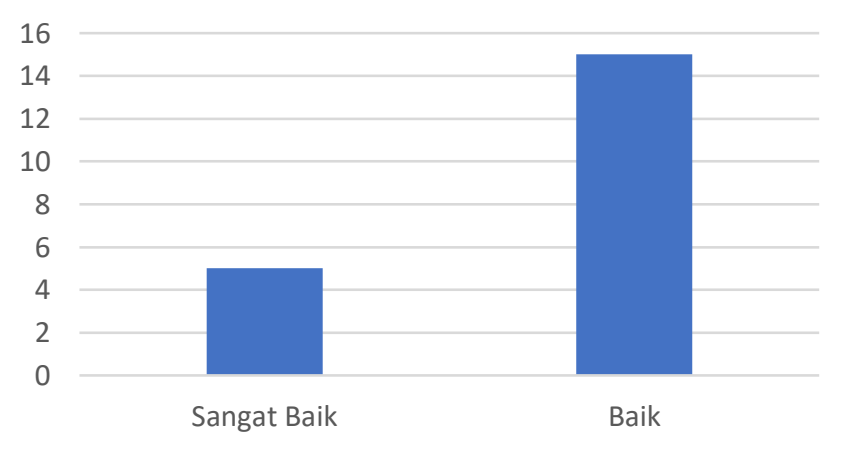

Gambar 12. Grafik Kuesioner setelah redesign web sekolah 


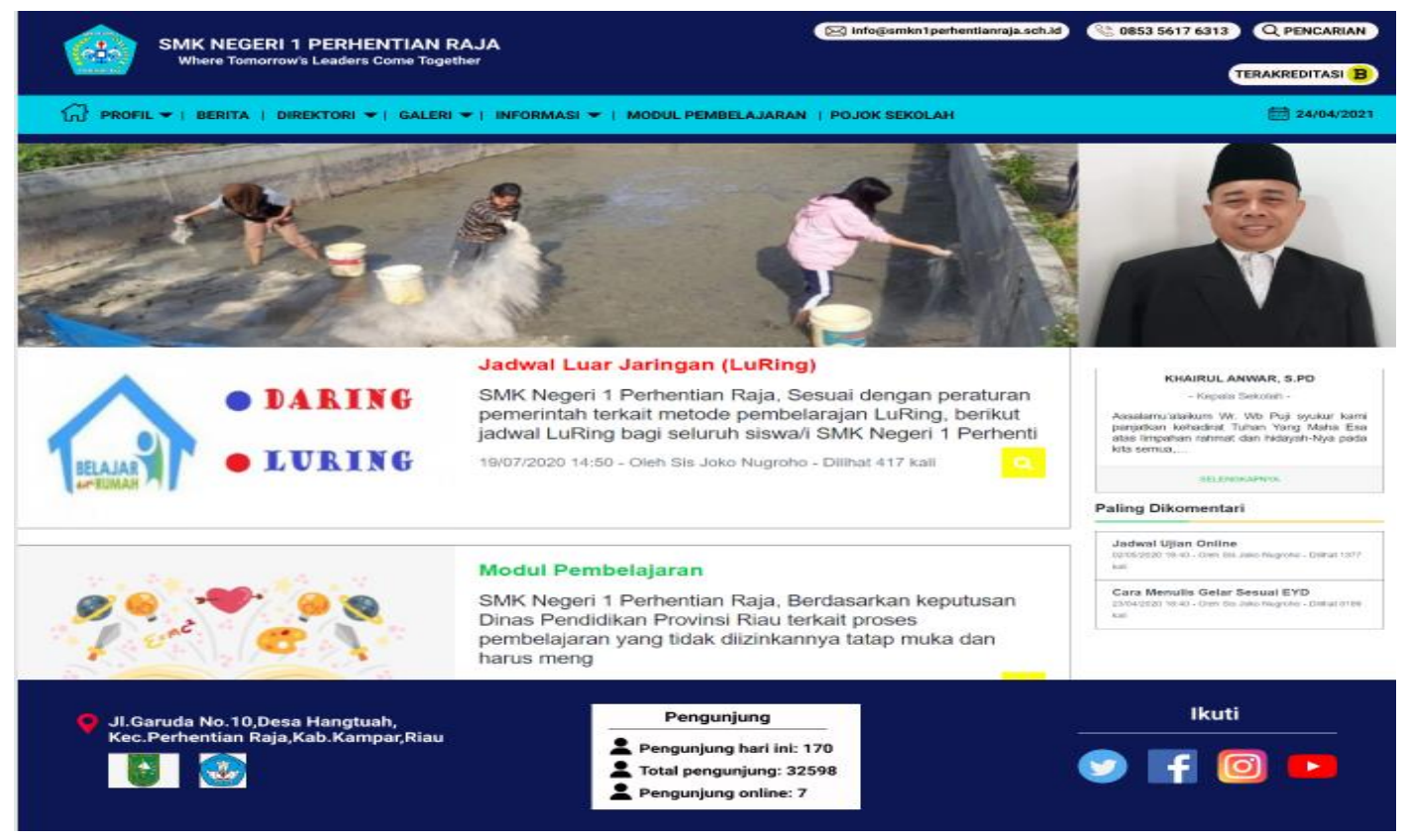

Gambar 13. Tampilan Web setelah redesign web sekolah

\section{KESIMPULAN}

Hasil penelitian ini menghasilkan web sekolah yang menarik dan informatif. Dengan solusi ini dapat membawa web sekolah menjadi wadah yang lebih menarik dan mudah dipahami dalam menyebarluaskan informasi. Adapun poin penting yang dapat diambil dari penelitian ini yakni menjadikan web sekolah sebagai media informasi yang dapat diterapkan di SMK N 1 Perhentian Raja. Sebagai media yang akurat dan terpercaya dalam menyampaikan informasi mulai dari info pembelajaran sampai evaluasi yang dilaksanakan oleh pihak sekolah. Mempermudah kinerja tenaga pengajar dalam menyimpan, edit dan publish data. Mempermudahkan siswa dalam mendapatkan informasi yang terpercaya.

\section{REFERENCES}

[1] F. A. Batubara, "Perancangan Website Pada Pt . Ratu Enim Palembang," REINTEK, pp. 15-27, 2012.

[2] A. Josi, "Penerapan Metode Prototyping Dalam Membangun Website Desa (Studi Kasus Desa Sugihan Kecamatan Rambang)," Jti, vol. 9, no. 1, pp. 50-57, 2017.

[3] Y. Adhipratama, "perancangan antar muka pengguna dengan metode lean UX pada website hello work dinas tenaga kerja kabupaten pasuruan," Director, vol. 15, no. 40, pp. 6-13, 2018, [Online]. Available: http://awsassets.wwfnz.panda.org/downloads/earth_summit_2012_v3.pdf\%0Ahttp://hdl.handle.net/10239/131\%0Ahttps:// www.uam.es/gruposinv/meva/publicaciones jesus/capitulos_espanyol_jesus/2005_motivacion para el aprendizaje Perspectiva alumnos.pdf\%0Ahttps://ww.

[4] D. A. Anggara, W. Harianto, A. Aziz, T. Informatika, U. Kanjuruhan, and S. Malang, "Prototipe Desain User Interface Aplikasi Ibu Siaga," vol. 4, pp. 58-74, 2021.

[5] M. A. Muhyidin, M. A. Sulhan, and A. Sevtiana, "Perancangan Ui/Ux Aplikasi My Cic Layanan Informasi Akademik Mahasiswa Menggunakan Aplikasi Figma," J. Digit, vol. 10, no. 2, p. 208, 2020, doi: 10.51920/jd.v10i2.171.

[6] R. Pramudita, R. W. Arifin, A. N. Alfian, N. Safitri, and S. D. Anwariya, "Penggunaan Aplikasi Figma Dalam Membangun Ui / Ux Yang Interaktif Pada Program Studi Teknik," J. Buana Pengabdi., vol. 3, no. 1, pp. 149-154, 2021.

[7] D. S. Prima Nur Hidayati Putri, "PENERAPAN SOFTWARE BALSAMIQ UNTUK MENINGKATKAN HASIL BELAJAR PADA MATA PELAJARAN KERJA PROYEK SISWA KELAS XII MULTIMEDIA DI SMK NEGERI 1 JOMBANG Prima," UNES Surabaya, vol. 1, pp. 1-7, 2018.

[8] D. Purnomo, "Model Prototyping Pada Pengembangan Sistem Informasi," J I M P - J. Inform. Merdeka Pasuruan, vol. 2, no. 2, pp. 54-61, 2017, doi: 10.37438/jimp.v2i2.67.

[9] E. N. A. Sufajar Butsianto1), "PENGEMBANGAN SISTEM INFORMASI PENJUALAN BERBASIS WEB MENGGUNAKAN METODE PROTOTYPING PADA TOKO BAY STICKER," SIGMA - J. Teknol. Pelita Bangsa, vol. 10, p. 275, 2020, doi: 10.35393/1730-006-002-014.

[10] J. Maulindar, "Prototype 'Smartcard Shop' Untuk," vol. 9, no. 1, pp. 1-14, 2020.

[11] F. N. Khasanah, S. Rofiah, and D. Setiyadi, "Metode User Centered Design Dalam Merancang Tampilan Antarmuka Ecommerce Penjualan Pupuk Berbasis Website Menggunakan Aplikasi Balsamiq Mockups," JAST J. Apl. Sains dan Teknol., vol. 3, no. 2, p. 14, 2019, doi: 10.33366/jast.v3i2.1443. 